\title{
BMJ Open Reduction in stillbirths at term after new birth induction paradigm: results of a national intervention
}

\author{
Mette Hedegaard, ${ }^{1}$ Øjvind Lidegaard, ${ }^{1}$ Charlotte Wessel Skovlund, ${ }^{1}$ \\ Lina Steinrud Mørch, ${ }^{1}$ Morten Hedegaard ${ }^{2}$
}

To cite: Hedegaard M, Lidegaard Ø, Skovlund CW, et al. Reduction in stillbirths at term after new birth induction paradigm: results of a national intervention. BMJ Open 2014;4:e005785. doi:10.1136/bmjopen-2014005785

- Prepublication history and additional material is available. To view please visit the journal (http://dx.doi.org/ 10.1136/bmjopen-2014005785).

Received 26 May 2014 Revised 19 July 2014 Accepted 24 July 2014

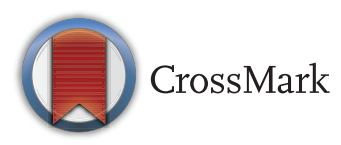

For numbered affiliations see end of article.

\section{Correspondence to}

Professor Øjvind Lidegaard; Oejvind.Lidegaard@regionh. $\mathrm{dk}$

\section{ABSTRACT}

Objective: The risk of fetal death increases steeply after 42 gestational weeks. Since 2009, Denmark has had a more proactive policy including prevention of prolonged pregnancy, and early intervention in women with diabetes, preeclampsia, high body mass index and of a higher age group. The aim of this study was to describe the development in fetal deaths with this more proactive birth induction practice, and to identify and quantify contributing factors for this development.

Design: National cohort study.

Setting: Denmark.

Participants: Delivering women in Denmark, 1 January 2000 to 31 December 2012.

Outcome measures: Stillbirths per 1000 women at risk (prospective risk of stillbirth) and per 1000 newborn from 37 and 40 gestational weeks, respectively, through the study period.

Results: During the study period, 829165 children were live born and $3770(0.45 \%)$ stillborn. Induction of labour increased from $12.4 \%$ in year 2000 to $25.1 \%$ in $2012(p<0.001)$, and the percentage of children born at or after 42 weeks decreased from $8.0 \%$ to $1.5 \%$ $(p<0.001)$. Through the same period, the prospective risk of stillbirth after 37 weeks fell from 0.70 to 0.41 / 1000 ongoing pregnancies $(p<0.001)$, and from 2.4 to $1.4 / 1000$ newborn $(p<0.001)$. The regression analysis confirmed the inverse association between year of birth and risk of stillbirth. The lowest risk was observed in the years 2011-2012 as compared with years 20002002 with a fully adjusted HR of $0.69(95 \% \mathrm{Cl} 0.57$ to $0.83)$. The general earlier induction, the focused earlier induction of women with body mass index $>30$, twins, and of women above 40 years and a halving of smoking pregnant women were all independent contributing factors for the decrease.

Conclusions: A gradually more proactive and differential earlier labour induction practice is likely to have mainly been responsible for the substantial reduction in stillbirths in Denmark.

\section{INTRODUCTION}

Fetal death is still a dreaded complication of pregnancy, not least when occurring at term. The worldwide number of stillborn infants is estimated at 2.6 million per year, and the

\section{Strengths and limitations of this study}

- Complete national data through a 13-year-long study period.

- Data analysed for all births after 37 weeks and after 40 weeks, respectively.

- Access to important confounders.

- Complete follow-up on all children born during the study period.

- A clear clinical message.

causes of a substantial number of these deaths are yet unknown. ${ }^{1}$ Identified risk factors include high maternal age, adiposity, fetal asphyxia, infections and different maternal medical diseases. ${ }^{2-5}$ Randomised studies have suggested a potential for prevention of fetal deaths by earlier induction of deliveries. $^{6}$

Over the past two decades, the discussion of induction of labour versus expectant management has been prevalent among obstetricians. ${ }^{7}$ A national Danish guideline in 2009 recommended induction of pregnant women ensuring delivery before 42 weeks. $^{8}$ Generally, pregnant women have since been offered labour induction at $42+3-5$, while women at risk (body mass index $>30$ or age $>40$ years) have been offered induction at 41 weeks. Lastly, women at a high risk such as women with multiple pregnancies, preeclampsia or intrauterine growth restriction are often recommended induction before term.

The aim of this study was to describe birth induction practice in Denmark since 2000, the corresponding development in post-term deliveries, and the stillbirth rates from 37 and 40 weeks of gestation, respectively (prospective stillbirth rate), and per 1000 newborn. Second, to adjust these trends in rates of stillbirth for important risk factors of stillbirth. 


\section{METHODS}

\section{Design and setting}

In a historical cohort design, data were collected from the Danish Birth Register, covering the period January 2000 through December 2012. The Registry is considered complete through this period. In order to reduce random variation, the 13-year study period was subdivided into five subperiods of 3, 3, 3, 2 and 2 years' length, respectively.

\section{Participants}

All live births and stillbirths during the study period were included. For each gestational day after 37 weeks, the number and distribution of all newborn and stillbirths were assessed. The gestational ages were generally assessed from first trimester ultrasound examinations. For the few women not attending this routine offer to all pregnant women in Denmark, the last menstrual period was used.

\section{Outcome measures}

Rates of stillbirth per 1000 ongoing pregnancies, also called the prospective risk of stillbirth, were calculated with a daily update from 37 weeks of gestation, accounting for the rapidly declining denominator, especially after term. ${ }^{9}$ The proportion of deliveries and of stillbirths after 37, 40, 41 and 42 weeks/1000 newborn were calculated annually from 2000 through 2012, and in different subperiods within this study period.

The gestational age was recorded in $99.4 \%$ of all newborn during the study period. Of 146 missing gestational ages among stillborn infants, we sought in medical charts and local registers and achieved this information in 42 women, all of whom had ended their pregnancy before 37 weeks. Therefore, all with a missing gestational age were allocated to the premature group. Gestational ages were, however, achieved for all stillbirths in 2011 and 2012.

From 2004, a birth has, in Denmark, been defined as any pregnancy that ends after 22 weeks of gestation and live born before 22 weeks. Before 2004, only live births between 22 and 28 weeks were considered as births, while delivery of dead fetuses before 28 weeks and live born before 22 weeks were considered as abortions. This technicality explains a minor increase in stillbirths before 37 weeks of gestation from 2003 to 2004 .

Deaths within the first week after delivery were assessed for all included live born and rates of death were calculated in each study year.

In the analytical assessment, analyses of the cumulative risk of stillbirth with increasing gestational age per 1000 ongoing pregnancies were estimated using a Nelson-Aalen estimator with gestational age (in days) as the time scale. ${ }^{10}$ By Cox regression analyses, the HRs of stillbirth by year of birth were estimated using year 2000-2002 as the reference group. Gestational age was underlying time scale in these analyses. The following potential confounders were included in the model: plurality, parity, maternal age, year, smoking and body mass index. The regression model aimed to quantify the contribution from each of the potential confounders for the association between calendar year and rates of stillbirth. ${ }^{10}$ HRs with $95 \%$ confidence limits were calculated, and $\mathrm{p}$ values below 0.05 were considered significant. Logistic regression was used to generate crude ORs.

The main analysis was carried out on all deliveries from 37 weeks of gestation. As body mass index was not routinely recorded in the birth registry until 2004, additional sensitivity analyses were carried out for the subperiod 2004-2012 in order to quantify specifically the influence of body mass index on the decreasing stillborn rate. Finally, sensitivity analyses were conducted restricted to singletons.

\section{RESULTS}

During the study period, 832935 children were born. Of these, $3770(0.45 \%)$ were stillbirths and 829165 (99.55\%) live born. The distribution of newborn and stillborn infants in different pregnancy weeks, the crude rate of stillborn per 1000 ongoing pregnancies and per 1000 newborn in different gestational weeks, from different gestational ages and in different periods are shown in table 1.

The frequency of birth induction increased from $12.4 \%$ in 2000 to $25.1 \%$ in 2012 , with a steep increase after 2010 (figure 1). The earlier birth induction reduced the percentage of children born from 42 weeks of gestation from $8 \%$ in 2000 to $1.5 \%$ in 2012 (figure 1). The increasing induction rate and fall in deliveries from 42 weeks were, however, already observable from 2001.

\section{Stillbirths with increasing gestational age}

The background for the new induction paradigm in Denmark is illustrated for the period 2000-2008 in figure 2. With increasing gestational age, the risk of fetal death rises, peaking after 43 weeks of gestation with more than 14 deaths $/ 1000$ ongoing pregnancies, a risk more than 10 times higher than in the weeks before term.

During the period 2009-2012, the stillborn rates were reduced $21-39 \%$, and stillbirths from $42+3$ were eliminated (figure 2).

The crude rates of fetal deaths with increasing gestational age were reduced by $30-66 \%$ when adjusting for age, year, parity, plurality and smoking (figure 3). Adjustment for body mass index did not change the estimates significantly.

\section{Stillbirths by time}

The rate of stillborn infants from 37 weeks of gestation decreased from 0.70 (95\% CI 0.64 to 0.77 ) per 1000 ongoing pregnancies (prospective stillbirth rate) during the period 2000-2002 to 0.41 (0.35 to 0.48 ) during the period 2011-2012 (figure 4). The corresponding rate of stillborn infants from 40 weeks fell from 1.8 (1.6 to 2.1) during the period 2000-2002 to 0.74 (0.56 to 0.98 ) 
Table 1 Rates* of live born and stillborn in and from different gestational weeks and periods in Denmark 2000-2012

\begin{tabular}{|c|c|c|c|c|c|c|c|c|}
\hline & 2000-2002 & 2003-2005 & 2006-2008 & 2009-2010 & 2011-2012 & 2000-2008 & 2009-2012 & 2000-2012 \\
\hline \multicolumn{9}{|c|}{ Number of live born and stillborn infants } \\
\hline Born (n) & 197222 & 194774 & 196023 & 127165 & 117751 & 588019 & 244916 & 832935 \\
\hline Stillborn (n) & 835 & 915 & 992 & 539 & 489 & 2742 & 1028 & 3770 \\
\hline \multicolumn{9}{|c|}{ Stillbirths per 1000 ongoing pregnancy weeks (prospective risk of stillbirth) } \\
\hline$<37$ & 0.22 & 0.20 & 0.21 & 0.17 & 0.17 & 0.21 & 0.17 & 0.20 \\
\hline $37+0-6$ & 0.39 & 0.46 & 0.39 & 0.27 & 0.23 & 0.41 & 0.25 & 0.37 \\
\hline $38+0-6$ & 0.36 & 0.51 & 0.46 & 0.41 & 0.34 & 0.44 & 0.38 & 0.42 \\
\hline $39+0-6$ & 0.56 & 0.54 & 0.63 & 0.44 & 0.46 & 0.57 & 0.45 & 0.54 \\
\hline $40+0-6$ & 1.20 & 0.95 & 0.97 & 0.93 & 0.76 & 1.04 & 0.85 & 0.98 \\
\hline $41+0-6$ & 2.29 & 2.40 & 1.73 & 1.35 & 0.54 & 2.15 & 0.98 & 1.82 \\
\hline $42+$ & 15.55 & 6.09 & 11.16 & 6.60 & 7.83 & 11.60 & 6.96 & 10.86 \\
\hline Total & 0.35 & 0.29 & 0.28 & 0.23 & 0.21 & 0.30 & 0.22 & 0.27 \\
\hline From 37 weeks & 0.70 & 0.67 & 0.63 & 0.50 & 0.41 & 0.67 & 0.46 & 0.61 \\
\hline From 40 weeks & 1.84 & 1.43 & 1.30 & 1.10 & 0.74 & 1.54 & 0.93 & 1.36 \\
\hline From 41 weeks & 3.12 & 2.46 & 2.09 & 1.51 & 0.69 & 2.60 & 1.14 & 2.21 \\
\hline \multicolumn{9}{|c|}{ Stillborn per 1000 newborn } \\
\hline From 37 weeks & 2.39 & 2.21 & 2.07 & 1.68 & 1.36 & 2.23 & 1.52 & 2.02 \\
\hline From 40 weeks & 2.11 & 1.59 & 1.41 & 1.20 & 0.77 & 1.71 & 0.99 & 1.50 \\
\hline From 41 weeks & 2.43 & 1.82 & 1.46 & 1.04 & 0.41 & 1.93 & 0.73 & 1.57 \\
\hline From 42 weeks & 3.16 & 1.05 & 1.55 & 0.82 & 0.95 & 2.04 & 0.86 & 1.79 \\
\hline
\end{tabular}

during 2011-2012, a reduction of $60 \% \quad(p<0.001)$. The fall was steepest from 2009-2010 to 2011-2012.

The rate of stillborn infants per 1000 newborn after 37 weeks demonstrated a similar decrease from $2.4(2.2$ to 2.6) during the period 2000-2002 to 1.4 (1.2 to 1.6) during 2011-2012, a fall of 43\% (figure 4). Among children born from 40 weeks, the corresponding stillborn rates fell from 2.1 (1.9 to 2.4) per 1000 newborn to 0.77 $(0.58$ to 1.0$)$ or by $63 \%(\mathrm{p}<0.001)$ (figure 4$)$.

\section{Regression analysis}

Several conditions that may have influenced the risk of fetal death changed during the study period (table 2).
The mean age of delivering women after 37 weeks of gestation increased from 30.1 years in 2000-2002 to 30.9 years in 2011-2012, and the proportion of delivering women $\geq 40$ years increased from $2.0 \%$ to $3.5 \%$ ( $p<0.001)$.

The mean body mass index increased from $24.1 \mathrm{~kg} / \mathrm{m}^{2}$ in 2003-2005 to $24.4 \mathrm{~kg} / \mathrm{m}^{2}$ during 2011-2012, and delivering women with a body mass index above $25 \mathrm{~kg} / \mathrm{m}^{2}$ increased from $32 \%$ to $34.4 \%$ through the same period $(\mathrm{p}<0.001)$.

While these changes are expected to increase the risk of fetal death, the proportion of pregnant smokers decreased from $20.5 \%$ in $2000-2002$ to $11.5 \%$ in $2011-2012$, almost a halving $(\mathrm{p}<0.001)$.
Figure 1 Proportion (\%) of induced deliveries and of children born from 41 and 42 weeks, respectively, in Denmark from 2000 to 2012. Number of children born: 832935 .

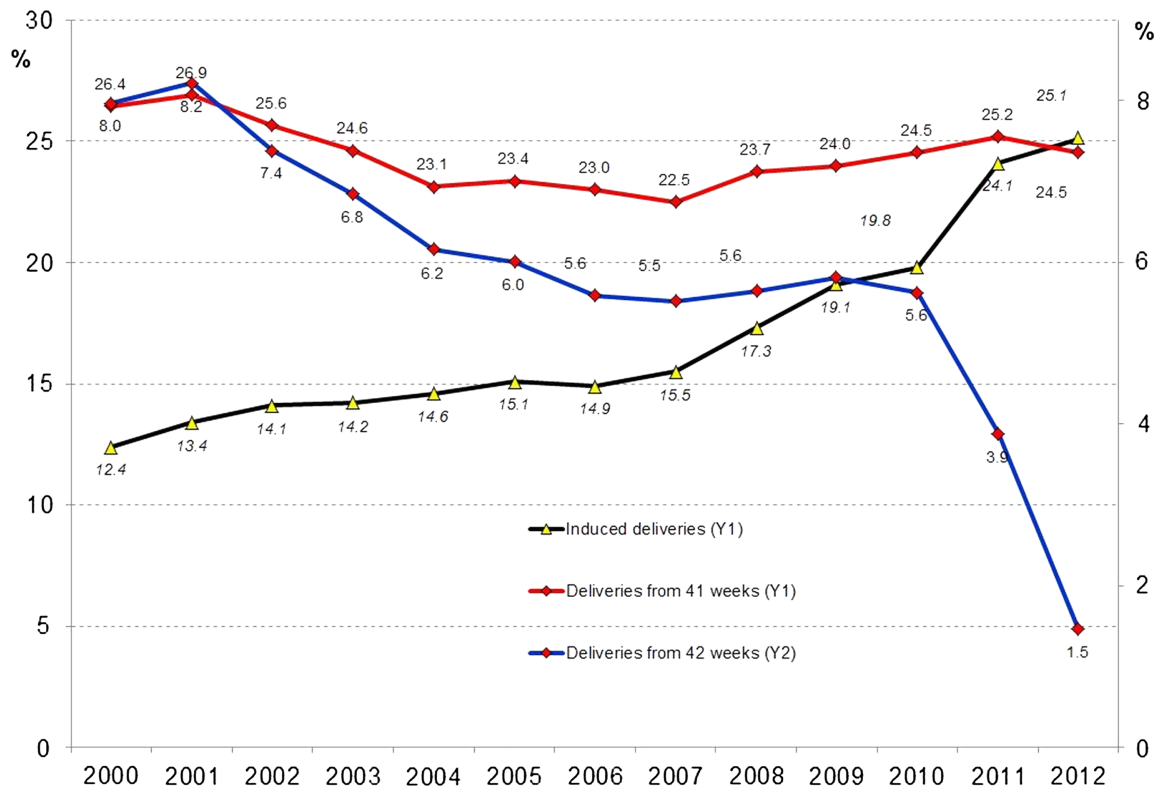


Figure 2 Fetal deaths per 1000 ongoing pregnancies according to gestational age during the periods 2000-2008 and 2009-2012. Number of weeks: 3406615. Number of fetal deaths: 3770 . Lower part the same in a semilogarithmic plot.

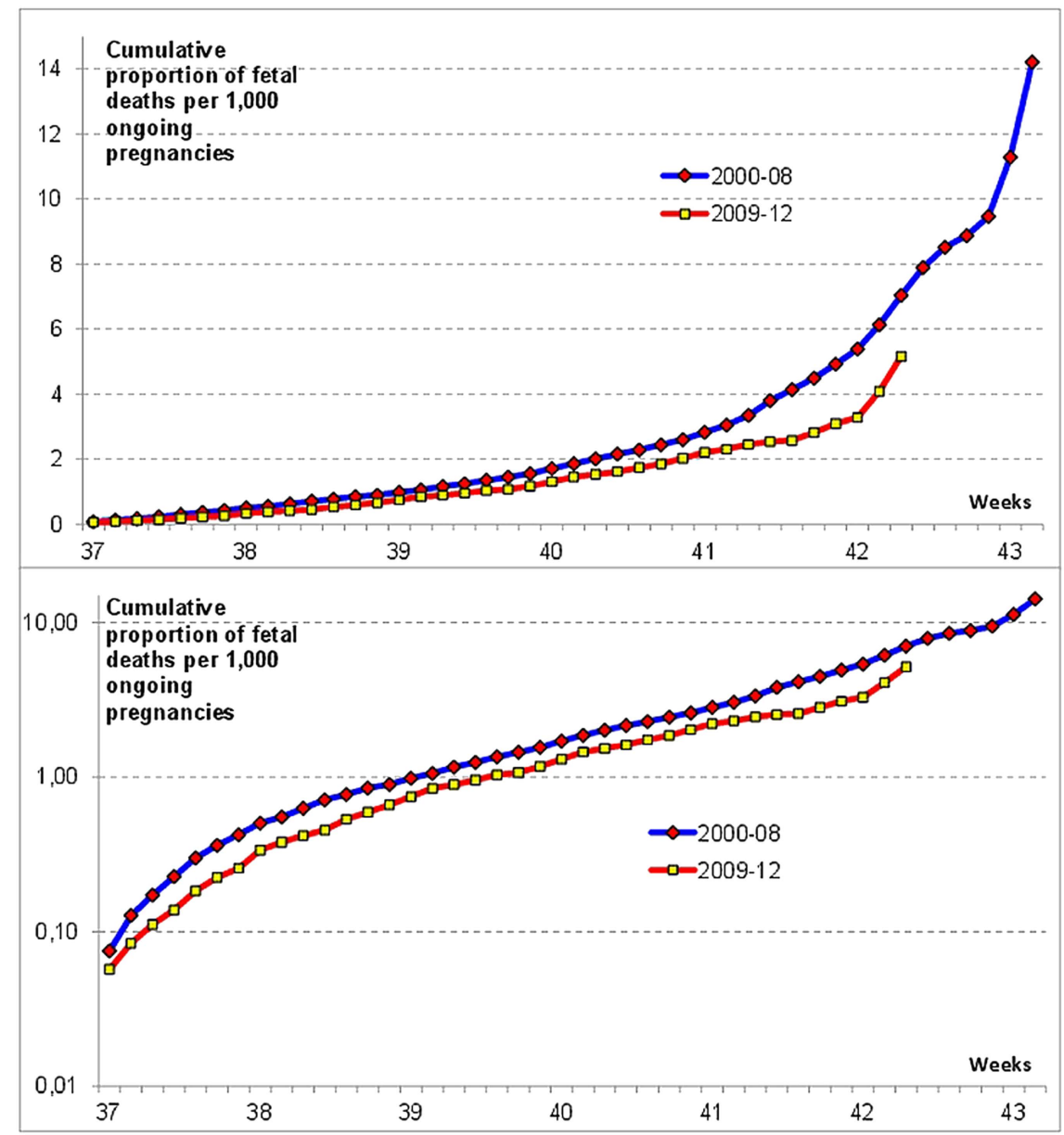

The proportion of primiparous increased slightly from $43 \%$ to $44.5 \%$ through the study period, while the proportion of multiple pregnancies after 37 weeks was almost stable: $2.4 \%$ in $2000-2002,2.6 \%$ in $2006-2008$ and $2.5 \%$ in 2011-2012 (table 2). The proportion of multiple deliveries after 40 weeks of gestation from an already low $0.12 \%$ decreased to $0.04 \%$. Thereby, postterm multiple deliveries almost disappeared through the study period.

In the fully adjusted model, the following HRs of fetal death were demonstrated: smoking 1.4 (1.2 to 1.6 ), body mass index $>25 \mathrm{~kg} / \mathrm{m}^{2}$; 1.5 (1.3 to 1.7 ), decreasing from 1.7 (1.4 to 2.0 ) during the period $2004-2008$ to 1.3 (1.0 to 1.6) in 2009-2012. Primiparous had a relative risk of stillbirth of 1.2 (1.1 to 1.3 ) and multiple pregnancy of 51.5 (44.4 to 59.6$)$.

With adjustment for gestational age at delivery, the decline in stillbirths was reduced from $-41.5 \%$ to $-35.5 \%$ suggesting that the general earlier induction in it self-accounted for about $15 \%$ of the reduction. Further adjustment for smoking, age at delivery and parity increased the fall from $-35.5 \%$ to $-37.6 \%$, because the decrease in smoking counterbalanced the influence of the slightly increasing age and proportion of primiparous by time. By additional adjustment for plurality, the relative risk of stillbirth by time was reduced from $-37.6 \%$ to $-31.4 \%$, suggesting that the changes in the management of twin pregnancies accounted for approximately $16 \%$ of the decrease.

In the subanalysis covering the period 2004-2012, during which information about body mass index was available, the decreasing risk of stillbirth among women with high body mass index by time implied a further nonsignificant $4 \%$ reduction in overall stillbirth rates by time.

The rest of the reduction in stillbirths is thus apparently due to the differential induction practice, where women with high-risk pregnancies are induced more proactively (earlier) than low-risk pregnancies.

The risk of fetal death in the week after term was reduced by $33-38 \%(\mathrm{p}<0.01)$, in the week after 41 weeks by $30-33 \%(\mathrm{p}<0.01)$ and after 42 weeks by 30-33\% $(\mathrm{p}<0.05)$ (figure 2). Thus, the new induction paradigm first moved deliveries from late weeks with a high risk of stillbirth to earlier weeks with a lower risk; second, in particular, moved high-risk pregnancies to earlier induction; and third, also reduced the risk of fetal death in each post-term week.

The decrease in the rate of stillbirth corresponds to a reduction in absolute numbers of stillborn infants after 37 weeks from 136 stillbirths per year to now about 75 per year, a reduction of approximately 60 per year $(p<0.001)$, corresponding to one saved stillborn infant per 1000 newborn.

During gestational weeks 37-40, the annual number of stillbirths fell from around 80 per year during the 
Figure 3 Crude fetal deaths per 1000 ongoing pregnancies according to gestational age during the period 2000-2012 and after adjustment for different confounders. *Lower part the same in a semilogarithmic plot.

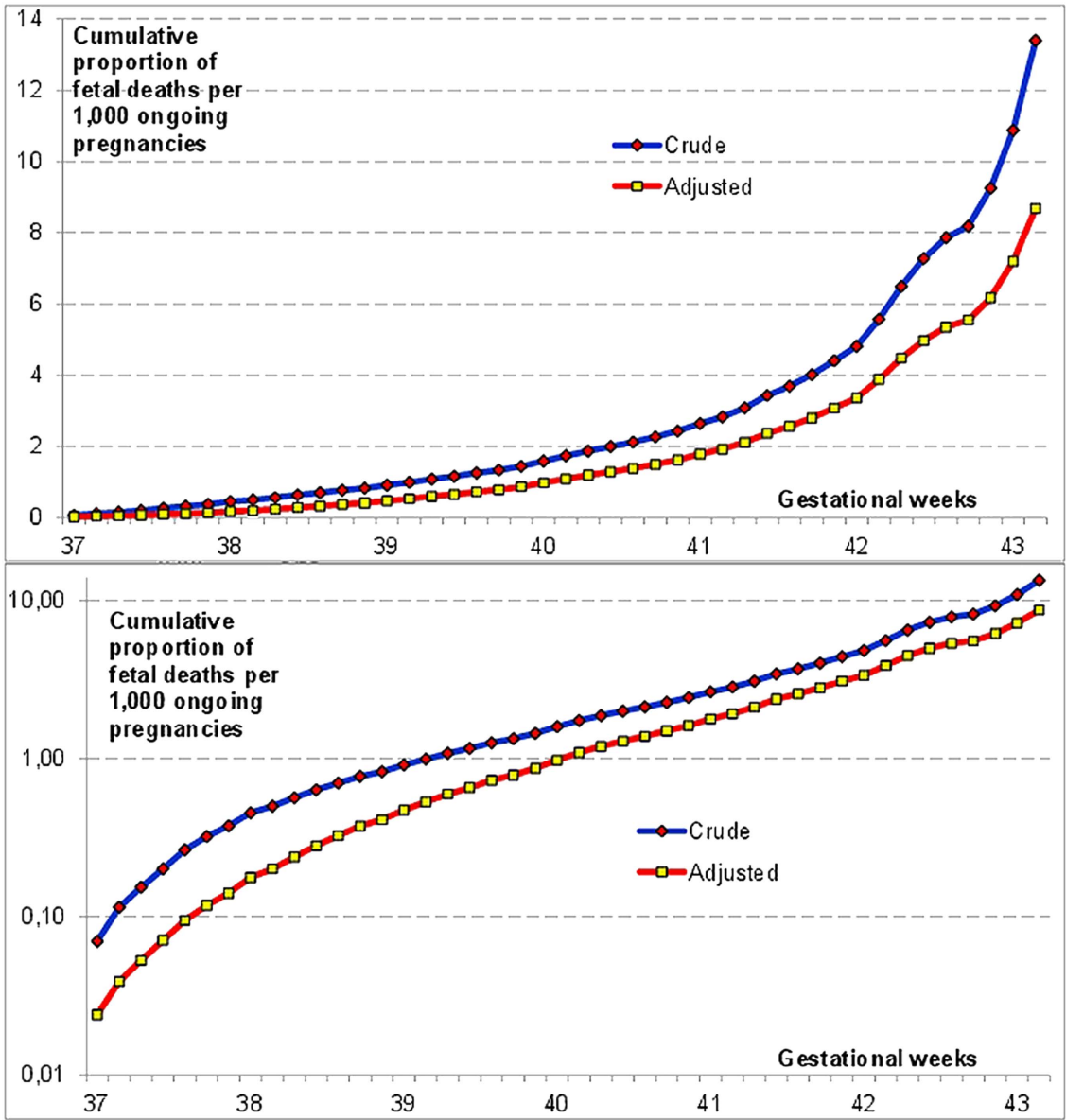

period 2000-2008 to 50 per year during 2009-2012. This reduction coincided with an increase in second trimester induced abortions on fetal indication from annually 292 during the period 2000-2008 to 410 per year during the period 2009-2012, an increase of 118 induced abortions per year. $^{11}$

The risk of dying during the first week of life was reduced among children born after 37 weeks from 1.7 (1.4-2.0) per 1000 newborn in 2000 to $0.8(0.6-1.0)$ per 1000 live born in 2012. ${ }^{12}$

The Caesarean section rate in Denmark has, after a steady increase over more than 40 years, been stable throughout the past 10 years at about $20 \%$ of all deliveries, even with a slight reduction from $20.4 \%$ in 2009 to $19.8 \%$ in $2012(\mathrm{p}<0.01) .^{12}$

The sensitivity analysis excluding women with unknown gestational age did not change anything after 37 weeks, but decreased slightly the risk of fetal deaths before 37 weeks (data not shown).

Sensitivity analyses restricted to singletons enhanced the fall in stillbirth rates by time. For all deliveries, the adjusted fall by time was $-31 \%$ and for singletons $-43 \%$.

\section{DISCUSSION}

We report a decrease in risk of fetal death after 37 weeks to $0.14 \%$ on a national level, which is the lowest risk ever reported in Denmark. Nor has any similar rate to our knowledge been published elsewhere.

Ever since the 1990s, there has been an ongoing discussion of induction of labour versus expectant management of women after term. ${ }^{7}$ Through the past 10 years, a gradually more proactive induction practice has gained ground over expectant management in several countries, including Denmark. The decision to make a Danish guideline in 2009 was stimulated by the NICE guideline on induction of labour published in 2008 and the American Congress of Obstetricians and Gynecologists (ACOG) practice bulletin from 2009. ${ }^{13} 14$

Before 2009, many women were still not offered induction until after they passed 42 weeks of gestation. From 2009, the recommended induction regimen prevented many pregnancies from reaching post-term gestational weeks of a high risk of fetal death. This change reduced the number of fetal deaths after term, but should in principle not influence the rate of deaths per 1000 ongoing pregnancies in a certain post-term week. The gestational age-specific stillbirth rate after 41 weeks was, however, also reduced. This reduction could not be explained by the general earlier induction practice, but is, according to our analyses, a result of an even more proactive induction practice in women at an increased risk of stillbirth, such as women with body mass index $>30$, and women over 40 years. An increased fetal monitoring after term by time may also have influenced the decrease. 
Figure 4 Fetal deaths per 1000 ongoing pregnancies (upper), and per 1000 newborn (lower) after 37 and 40 gestational weeks, respectively, in different subperiods from year 2000 to 2012. 95\% confidence limits indicated.
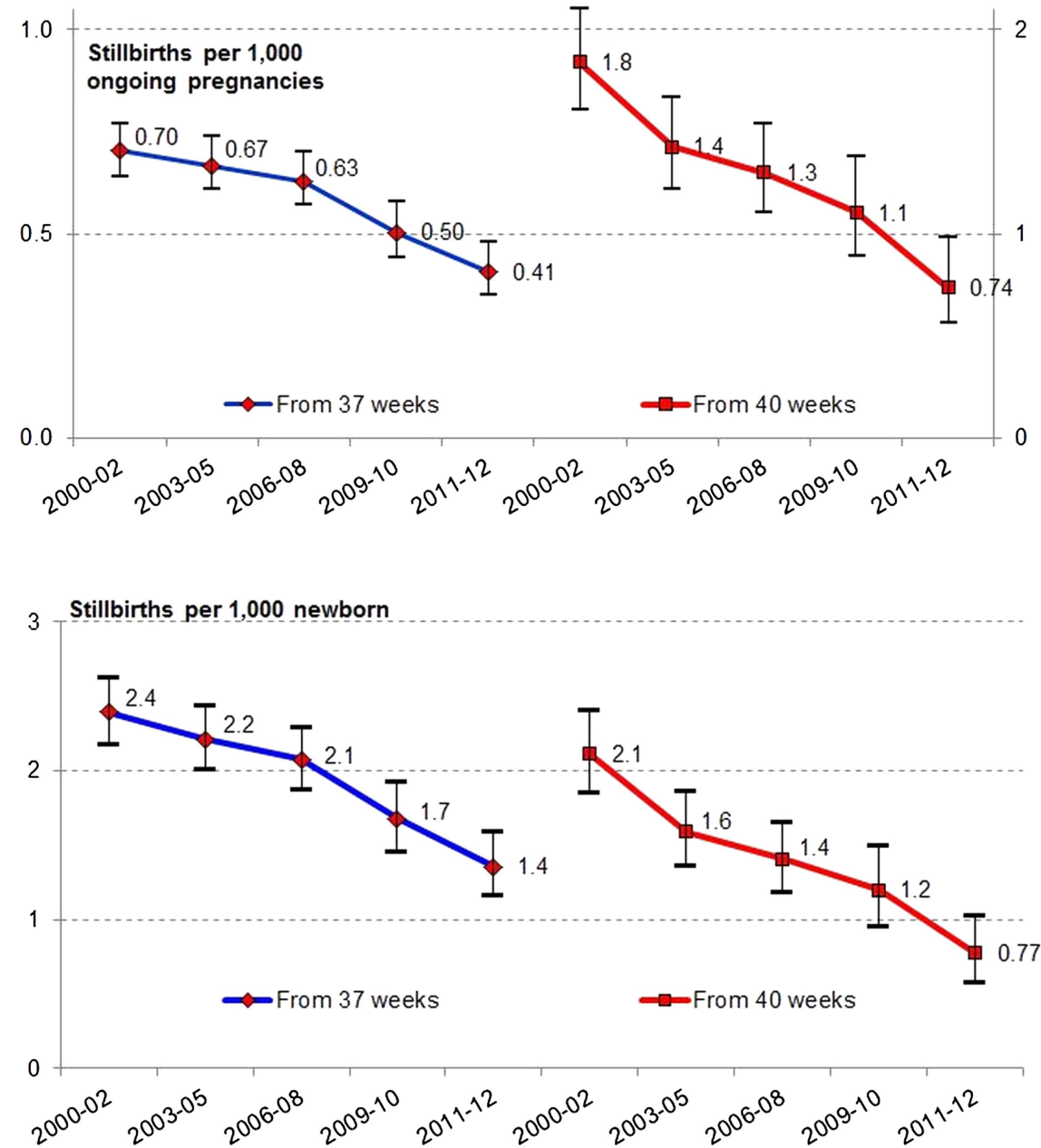

Through the past 10 years, the majority of Danish units have used misoprostol for induction of labour, either applied vaginally or orally. It has been questioned whether induction by misoprostol could increase the risk of uterine hyperstimulation, asphyxia and ultimately of neonatal death. In theory, an initiative to reduce the risk of fetal death could lead to neonatal complications and neonatal death. It is, therefore, important that the reduction in stillbirths was not associated with an increase in early neonatal deaths. On the contrary, the early neonatal deaths were halved during the study period, a circumstance that undoubtedly was also influenced by improved neonatal care through the study period.

It has been discussed whether induction of labour causes more Caesarean sections. ${ }^{15}$ Some have argued that expectant management of labour increases the Caesarean section rate due to the risks associated with prolonged pregnancy. ${ }^{16}$ The slight reduction in Caesarean sections with the new induction paradigm demonstrates that a proactive induction practice does not necessarily increase the frequency of surgical interventions.

The offer of first trimester combined screening (double test and nuchal translucency scan) has, in
Denmark, been widened to all pregnant women from 2005 to $2006 .{ }^{17}$ Before then, only women 35 years or older were routinely offered first-trimester screening. With the new routine, a majority of chromosomal abnormalities are detected and pregnancy most often terminated, accounting for the increase of approximately 118 annual second trimester induced abortions. Before the general screening was fully implemented, some fetuses with undetected abnormalities died later in pregnancy. From 20 weeks of gestation until term, $13 \%$ of trisomy $21,75 \%$ of trisomy 18 and $35 \%$ of trisomy 13 experience fetal death, ${ }^{18}$ a majority of these before 37 gestational weeks. This circumstance may explain a reduction of about 15 fetal deaths per year, but only about 7 after 37 weeks corresponding to $12 \%(7 / 60)$ of the observed reduction in stillborn infants.

During the study period, the quality of screening for structural abnormalities (offered in general throughout the period) and Doppler ultrasound improved the monitoring of fetuses in utero, making it easier to detect threatened fetuses and to intervene to avoid further complications including fetal death. However, these circumstances are probably of minor importance for the decrease in stillbirths, as other countries with the same technical improvement have not observed a similar 
Table 2 Characteristics of women giving birth at term and relative risk of stillbirth by time

\begin{tabular}{|c|c|c|c|c|c|}
\hline & 2000-2002 & 2003-2005 & 2006-2008 & 2009-2010 & 2011-2012 \\
\hline Mean age (years) & 30.1 & 30.6 & 30.8 & 30.9 & 30.9 \\
\hline Mother $\geq 40$ years & 3584 & 4366 & 5436 & 3740 & 3777 \\
\hline$\% \geq 40$ years & 2.0 & 2.4 & 3.0 & 3.2 & 3.5 \\
\hline BMI recorded (n) & NA & 112635 & 167962 & 111972 & 106201 \\
\hline Mean BMI & NA & 24.1 & 24.2 & 24.3 & 24.4 \\
\hline $\mathrm{BMI}>25$ & NA & 36076 & 54903 & 37616 & 36528 \\
\hline$\%$ BMI > 25 & NA & 32.0 & 32.7 & 33.6 & 34.4 \\
\hline $\mathrm{BMI}>30$ & NA & 12480 & 19683 & 13946 & 13720 \\
\hline$\%$ BMI >30 & NA & 11.1 & 11.7 & 12.5 & 12.9 \\
\hline $\mathrm{BMI}>35$ & NA & 4032 & 6813 & 4880 & 4689 \\
\hline$\%$ BMI > 35 & NA & 3.6 & 4.1 & 4.4 & 4.4 \\
\hline Smoker & 37540 & 30782 & 25656 & 14891 & 12527 \\
\hline$\%$ smokers & 20.5 & 17.1 & 14.2 & 12.6 & 11.5 \\
\hline Multiple pregnancies & 4353 & 4617 & 4727 & 3116 & 2747 \\
\hline$\%$ multiples & 2.4 & 2.6 & 2.6 & 2.6 & 2.5 \\
\hline Stillborn multiples & 51 & 111 & 61 & 40 & 29 \\
\hline \% stillborn multiples & 1.2 & 2.4 & 1.3 & 1.3 & 1.1 \\
\hline Para 0 & 78718 & 77231 & 77685 & 51675 & 48584 \\
\hline$\%$ Para 0 & 43.0 & 42.9 & 43.0 & 43.8 & 44.5 \\
\hline Regression analysis & \multicolumn{5}{|c|}{ HR $^{\star}$ of stillborn (2000-2002 reference) } \\
\hline Crude & 1 & 0.95 & 0.89 & 0.72 & 0.59 \\
\hline Adjusted for GA & 1 & 1.02 & 0.98 & 0.78 & 0.65 \\
\hline $95 \% \mathrm{Cls}$ & & 0.89 to 1.17 & 0.85 to 1.12 & 0.66 to 0.92 & 0.53 to 0.78 \\
\hline Adjusted except plurality $¥ \S$ & 1 & 1.03 & 0.89 & 0.73 & 0.62 \\
\hline $95 \%$ Cls & & 0.90 to 1.18 & 0.78 to 1.03 & 0.61 to 0.86 & 0.52 to 0.75 \\
\hline Fully adjusted & 1 & 1.07 & 0.96 & 0.78 & 0.69 \\
\hline $95 \%$ Cls & & 0.93 to 1.23 & 0.83 to 1.11 & 0.65 to 0.92 & 0.57 to 0.83 \\
\hline
\end{tabular}

decrease in stillbirths. In Sweden, the proportion of deliveries after 42 weeks was $7.5 \%$ in 2000 and $6.5 \%$ in 2011. During the same period, the stillbirth rate after 37 gestational weeks was stable between 1.6 and $1.9 / 1000$ newborn. ${ }^{19}$ In Norway, $4.8 \%$ of deliveries occurred at 42 weeks or later and the stillbirth rate after 37 weeks was $1.47 / 1000$ newborn, ${ }^{20}$ figures close to Danish figures in 2010.

The earlier induction of multiple pregnancies explained about $15 \%$ of the reduction in stillbirths. The selective early induction of high-risk pregnancies such as pregnancies in women with high body mass index, women above 40 years, and women with multiple pregnancies explains why the impact of these risk factors decreased by time. Worldwide, maternal age at delivery has increased over the past five decades, and Denmark is no exception. ${ }^{21}$ As high maternal age is associated with stillbirth, this increase should have increased the stillbirth rates slightly by time. ${ }^{522} 23$

Determining the optimal time to deliver necessarily involves balancing induction risks and benefits. According to earlier studies, the risks of post-term deliveries include an increased perinatal mortality, meconium aspiration, macrosomnia, low umbilical cord artery $\mathrm{pH}$ and low Apgar score at 5 min. ${ }^{24}$ Inducing labour too early, on the other hand, may cause iatrogenic prematurity and respiratory complications. ${ }^{25} 26$

When considering the overall risk of either fetal or infant death, previous studies have suggested the risk of expectant management to be lower than the risk of delivery until about 38 weeks. Passing 38 weeks, the risk of expectant management was found to be higher than the risk of delivery, and the risk difference increases substantially after 40 and 41 weeks of gestation, favouring delivery over expectant management. ${ }^{27}$

A Scottish historical cohort study by Stock et $a l^{28}$ similarly demonstrated a substantial lower perinatal mortality in women induced at 41 weeks as compared with expectant management: $\mathrm{OR}=0.30$ (95\% CI 0.20 to 0.46$)$.

Among the strengths of this study are the almost complete coverage of deliveries ${ }^{29}$ and access to data, making possible an evaluation of circumstances that might have influenced the stillbirth rates. The main limitation is the observational design and the difficulty to account effectively for all potential confounders. The significant reduction in fetal deaths seen in Denmark has not been observed in Sweden, where the handling of post-term pregnancies has undergone less change. ${ }^{19}$

In conclusion, the striking decrease in risk of late fetal deaths through recent years is likely primarily to be due 
to the earlier and increased induction rate. The additional health costs to save these lives were low, and the reduction was obtained without an increase in surgical interventions.

An important issue that needs further studies is the morbidity in newborn through the same study period to confirm that the reduced mortality is not at the expense of an increased morbidity in newborn.

Denmark already had a low stillbirth rate a decade ago. ${ }^{1}$ With the further reduction in stillbirths, we may now have achieved the lowest stillbirth rate ever reported. We see no reason why a similar, more proactive induction paradigm could not be implemented in other countries, with further reduction in late stillbirths succeeding worldwide.

\section{Author affiliations}

${ }^{1}$ Department of Gynecology, Faculty of Health Science, Rigshospitalet, University of Copenhagen, Copenhagen, Denmark

${ }^{2}$ Department of Obstetrics, Faculty of Health Science, Rigshospitalet, University of Copenhagen, Denmark

Contributors $\mathrm{MeH}, \mathrm{MoH}$ and $\emptyset \mathrm{L}$ planned the study. CWS retrieved data from the National Birth Registry and National Health Registry. LSM, ØL and CWS analysed the data. MeH and ØL wrote the manuscript. All authors revised the manuscript and accepted the final version. $\mathrm{MoH}$ is the guarantor.

Funding The study was supported by a scholar grant from Rigshospitalet. Other expenses were covered by Department of Gynaecology, Rigshospitalet, University of Copenhagen.

Competing interests $\varnothing \mathrm{L}$ within the past 3 years received honoraria for speeches in pharmacoepidemiological issues.

Ethics approval The study was approved by the Danish Data Protection Agency (J.no: 2013-41-2063) and the National Board of Health (J.no, FSEID 00000579).

Provenance and peer review Not commissioned; externally peer reviewed.

Data sharing statement No additional data are available.

Open Access This is an Open Access article distributed in accordance with the Creative Commons Attribution Non Commercial (CC BY-NC 4.0) license, which permits others to distribute, remix, adapt, build upon this work noncommercially, and license their derivative works on different terms, provided the original work is properly cited and the use is non-commercial. See: http:// creativecommons.org/licenses/by-nc/4.0/

\section{REFERENCES}

1. Cousens $\mathrm{S}$, Blencowe $\mathrm{H}$, Stanton $\mathrm{C}$, et al. National, regional, and worldwide estimates of stillbirth rates in 2009 with trends since 1995: a systematic analysis. Lancet 2011;377:1319-30.

2. The Stillbirth Collaborative Research Network Writing Group. Causes of death among stillbirths. JAMA 2011;306:2459-68.

3. Page JM, Snowden JM, Cheng YW, et al. The risk of stillbirth and infant death by each additional week of expectant management stratified by maternal age. Am J Obstet Gynecol 2013;209:375.e1-7.

4. Flenady V, Koopmans L, Middleton P, et al. Major risk factors for stillbirth in high-income countries: a systematic review and meta-analysis. Lancet 2011;377:1331-40.

5. Flenady V, Middleton P, Smith GC, et al. Stillbirths: the way forward in high-income countries. Lancet 2011;377:1703-17.
6. Gülmezoglu AM, Crowther CA, Middelton P, et al. Induction of labour for improving birth outcomes at or beyond term (Review). Cochrane Database Syst Rev 2012;6:1-329.

7. Hannah ME, Hannah WJ, Hellmann J, et al. Induction of labor as compared with serial antenatal monitoring in post-term pregnancy. A randomized controlled trial. N Engl J Med 1992;326:1587-92.

8. Sandbjerg guidelines[internet]. Graviditas prolongata [Danish]. http:// clin.au.dk/fileadmin/www.ki.au.dk/forskning/forskningsenheder/gyn kologisk-obstetrisk_afd y/logistics/sandbjerg $m$ der/sandbjerg 2011/Graviditas_prolongata2011_1.pdf (accessed 13 Mar 2014).

9. Yudkin PL, Wood L, Redman CW. Risk of unexplained stillbirth at different gestational ages. Lancet 1987:1:1192-4.

10. Smith GCS. Estimating risks of perinatal death. Am J Obstet Gynecol 2005;192:17-22.

11. Lidegaard Ø. Early pregnancy and abortions. Annual report for year 2012 [Danish]. National Quality Database for Early Pregnancy and Abortions. 2013. http://www.tigrab.dk (accessed 13 Mar 2014).

12. Danish birth registry online. http://www.ssi.dk/Sundhedsdataogit/ Dataformidling/Sundhedsdata/Fodsler/Fodte\%201973.aspx (accessed 7 Aug 2013)

13. Induction of Labour. NICE Guideline (CG70), July 2008. http:// guidance.nice.org.uk/CG70 (accessed 13 Mar 2014).

14. Clinical management guidelines for obstetrician-gynecologists. Induction of labor. ACOG Practice bulletin (107), August 2009. http:// www.pqcnc.org/documents/sivbdoc/sivbeb/2ACOG2009Practice Bulletin107InductionofLabor.pdf (accessed 13 Mar 2014).

15. Heffner LJ, Elkin E, Fretts RC. Impact of labor induction, gestational age, and maternal age on caesarean delivery rates. Obstet Gynecol 2003;102:287-93.

16. Caughey $A B$. Perinatal outcomes related to induction of labor: a call for randomized trials. Am J Obstet Gynecol 2013:209:168-9. http:// dx.doi.org/10.1016/j.ajog.2013.07.011 (accessed 24 Feb 2014)

17. Ekelund CK, Jørgensen FS, Petersen OB, et al. Impact of new national screening policy for Down's syndrome in Denmark: population based cohort study. BMJ 2008;337:a2547.

18. Nicolaides $\mathrm{KH}$. Nuchal translucency and other first-trimester sonographic markers of chromosomal abnormalities. Am J Obstet Gynecol 2004;191:45-67.

19. Socialstyrelsen. Pregnancies, deliveries and newborn. Medical Birth Registry 1973-2011. Assisted reproduction 1991-2010. [Swedish]. National Board of Health [Hälso- och Sjukvård] 2013. http://www. socialstyrelsen.se/publikationer2013/2013-2-7 (accessed 13 Mar 2014).

20. Ebbing M, Klungsøyr K. Deliveries in Norway 2011. [Norweigian] Folkehelseinstituttet 2013. http://www.fhi.no/dokumenter/2a92108f4f. pdf (accessed 24 Jan 2014).

21. Statistics of Denmark. http://www.statistikbanken.dk/statbank5a/ default.asp? $\mathrm{W}=1024$ (accessed 13 Mar 2014).

22. Fretts RC, Schmittdiel J, McLean FH, et al. Increased maternal age and the risk of fetal death. N Engl J Med 1995;333:953-7.

23. Reddy UM, Ko CW, Willinger M. Maternal age and the risk of stillbirth throughout pregnancy in the United States. Am J Obstet Gynecol 2006;195:764-70.

24. Kaimal AJ, Little SE, Odibo AO, et al. Cost-effectiveness of elective induction of labor at 41 weeks in nulliparous women. Am J Obstet Gynecol 2011;204:137. e1-9.

25. Clark SL, Frye DR, Meyers JA, et al. Reduction in elective delivery at $<39$ weeks of gestation: comparative effectiveness of 3 approaches to change and the impact on neonatal intensive care admission and stillbirth. Am J Obstet Gynecol 2010;203:e1-6.

26. Agency for Healthcare Research and Quality [internet]. Evidence report number 176: Maternal and Neonatal Outcomes of Elective Induction of Labor. http://www.ahrq.gov/research/findings/evidencebased-reports/eil-evidence-report.pdf (accessed 13 Mar 2014).

27. Rosenstein MG, Cheng YW, Snowden JM, et al. Risk of stillbirth and infant death stratified by gestational age. Obstet Gynecol 2012;120:76-82.

28. Stock SJ, Ferguson E, Duffy A, et al. Ourcomes of elective induction of labour compared with expectant management: population based study. BMJ 2012;344:e2838.

29. Blenstrup LT, Knudsen LB. Danish registers on aspects of reproduction. Scand J Public Health 2011;39(Suppl 7):79-82. 